\title{
Anarquismo y cuestión sexual en el periódico Acción libertaria (Argentina, 1933-1955)
}

Anarquism and sexual issue in the newspaper Acción libertaria (Argentina, 1933-1955)

\author{
Laura Fernández Cordero*
}

Resumen: Se ha demostrado que la cuestión sexual - entendida como un conjunto de argumentaciones relacionadas con la emancipación de la mujer, el ejercicio de la sexualidad, la reproducción, la homosexualidad, la moral sexual, entre otros tópicos - fue central en la prensa anarquista de la Argentina entre fines del siglo XIX y las primeras décadas del XX. La hipótesis general de la que parte este artículo afirma que, mientras las publicaciones culturales y los proyectos editoriales anarquistas o con protagonismo anarquista se abocaron a la difusión de saberes relacionados con la cuestión sexual, los sectores más comprometidos con una reorganización orgánica y federal del anarquismo, y con una fuerte opción por una estrategia sindical, dieron menos espacio y profundidad en sus periódicos a esa problemática. Si bien, algunos de sus tópicos no se encontraban ausentes, la mayor parte de los discursos se circunscribieron a uno de los elementos menos controvertidos del ideario: la "emancipación de la mujer". Con el fin de poner a prueba esa hipótesis, se analizan los primeros veinticinco años de edición del periódico Acción Libertaria.

Palabras clave: Anarquismo, cuestión sexual, Argentina, prensa

\begin{abstract}
The "sex issue" was central in the anarchist press in Argentina between late 19th century and the first decades of the 20th. It is also known that the anarchist influence on the subject continued through cultural magazines and books published by leftist movements. This article explores other written matter to confirm the hypothesis that sectors committed to reorganization of anarchism in the thirties gave less space in their newspapers to this issue. However, "women's emancipation" was a recurring topic. In order to test the hypothesis, this article analyzes the first twenty-five years of the newspaper Acción Libertaria.
\end{abstract}

Keywords Anarquism, sexual issue, Argentina, press

Recibido: 6 de junio 2019 Aceptado: 18 octubre 2019

\footnotetext{
* Argentina. Dra. en Ciencias Sociales por la Universidad de Buenos Aires. Investigadora del Consejo Nacional de Investigaciones Científicas y Técnicas (CONICET) con sede en el Centro de Documentación e Investigación de la Cultura de Izquierdas (CeDInCI/UNSAM). lfernandezcordero@cedinci.org
} 


\section{Introducción}

El ideario anarquista es revolucionario, internacional y vasto. Además de la consabida crítica al Estado y el decidido anticlericalismo, se cuentan entre sus principales desvelos las cuestiones relacionadas con la emancipación de la mujer, el amor libre y la sexualidad. Para el caso argentino, el libro de Dora Barrancos - Anarquismo, educación y costumbres en la Argentina de principios de siglo - se convirtió en un clásico que estableció los lineamientos rectores al momento de analizar lo que era una zona novedosa de la historiografía anarquista. ${ }^{1}$ Otras autoras, como Maxine Molyneux, María del Carmen Feijoó y Mabel Bellucci fueron también pioneras en la visibilización de las mujeres anarquistas locales y sus producciones dentro de la prensa libertaria entre fines del siglo XIX y las primeras tres décadas del siglo XX. Sus trabajos abrieron una senda muy fecunda que todavía está en plena producción, y que va explorando numerosas aristas de la "cuestión sexual", términos con los que sintetizaremos un núcleo de preocupaciones ligadas al ideal de Revolución Social y que giraban en torno a la emancipación de la mujer y a las relaciones afectivas y sexuales. ${ }^{2}$

Así se ha demostrado que, al igual que en otras latitudes, esa cuestión estaba muy presente en notas e intercambios polémicos que se sucedían en numerosas publicaciones. Los discursos más estables apuntaban a criticar la institución matrimonial y, sin que se llegara a un acuerdo general, se debatían entre dos versiones: uniones libres como monogamias sucesivas que comenzaban y terminaban por simple afinidad, y amores libres experimentales que podían incluir a más de dos personas (aunque en un estricto marco heterosexual). Si bien la maternidad era un valor muy apreciado, se abogaba por una "maternidad consciente" mediante la cual era posible acotar la cantidad de nacimientos y, para ello, se distribuía información sobre métodos anticonceptivos. Estos saberes eran tributarios de la corriente neomalthusiana que comenzaba a difundirse desde algunos países europeos y encontraba eco en las izquierdas locales. ${ }^{3}$

Una pionera hipótesis de Dora Barrancos en torno a este conjunto de argumentaciones afirma que a los debates centrados en el placer les siguió una sostenida tendencia hacia la medicalización. De un primer momento de apertura que propugnaba diversas formas de amor libre, se habría pasado a otra instancia, más dominada por una

\footnotetext{
${ }^{1}$ Dora Barrancos, Anarquismo, educación y costumbres en la Argentina de principios de siglo, Buenos Aires, Contrapunto, 1990.

2 María del Carmen Feijoó, Las feministas, Buenos Aires, Centro Editor de América Latina, 1982. Maxine Molyneux, "No God, No Boss, No Husband: Anarchist Feminism in Nineteenth-Century Argentina", Latin American Perspectives, Vol. 13, $\mathrm{n}^{\circ}$ 1, Latin America's Nineteenth-Century History, 1986, 119-145. Hay versión en español: "Ni Dios, ni Patrón, ni marido. Feminismo anarquista en la Argentina del siglo XIX", La Voz de la Mujer, Periódico comunista-anárquico, Buenos Aires, Universidad Nacional de Quilmes, 1997. Mabel Bellucci, “Anarquismo, sexualidad y emancipación femenina. Argentina alrededor del 900", Nueva Sociedad, n¹09, 1990, 148-157. Fernanda Losso, La intervención discursiva de periódicos escritos por mujeres en la propaganda anarcocomunista, Tesis de Licenciatura, Universidad Nacional de La Plata, 2015. Nadia Ledesma Prietto, La revolución sexual de nuestro tiempo. El discurso médico anarquista sobre el control de la natalidad, la maternidad y el placer sexual (Argentina, 1931-1951), Buenos Aires, Biblos, 2016. Laura Fernández Cordero, Amor y anarquismo. Experiencias pioneras que pensaron y ejercieron la libertad sexual, Buenos Aires, Siglo XXI, 2017.

${ }^{3}$ Eduard Masjuan, "Procreación consciente y discurso ambientalista: anarquismo y neomalthusianismo en España e Italia, 1900-1936”, Ayer. Revista de Historia Contemporánea, n 46, Madrid, 2002, 63-92.
} 
perspectiva médica permeada por la preocupación eugenésica. Con el objetivo, entre otros, de problematizar esa lectura, Nadia Ledesma Prietto avanzó sobre las décadas posteriores al año 1930, cierre clásico de la historiografía anarquista local. ${ }^{4}$ Entre los años treinta y sesenta, señaló el protagonismo de los médicos anarquistas Juan Lazarte y Manuel Martín Fernández quienes participaban de publicaciones pertenecientes al amplio arco de las izquierdas. Al revisar revistas como "Cultura Sexual y Física" y "Hombre de América" demostró que, a través del correo de lectores y documentadas notas de divulgación, estos profesionales de la medicina sostuvieron un discurso que excedía la clave médica, insistía en separar la sexualidad de la procreación y propiciaba el placer femenino. Según sus hipótesis más recientes, incluso ambos serían ineludibles para delinear una genealogía de la sexología en el país. ${ }^{5}$ En este sentido, Ledesma Prietto sigue la línea abierta por Richard Cleminson quien hace una certera crítica a los estudios que aíslan al anarquismo del conjunto de discursos propios de la época y provocan una falsa singularidad. ${ }^{6}$ Este autor, dedicado al análisis del anarquismo catalán y valenciano, advierte, además, que los estudios sobre los aspectos vinculados a la sexualidad se están desarrollando recién en la última década, y han permanecido demasiado acotados por la historiografía ligada a la historia de las mujeres y al concepto de género.

Estos dos trabajos previos en diálogo han demostrado el fuerte compromiso del anarquismo en la difusión de saberes relacionados con la cuestión sexual, en especial, a través de revistas culturales. Para el caso argentino que nos ocupa, Ledesma Prietto construyó un corpus que recorre los años treinta, cuarenta y primeros cincuenta, y que incluye la revista "Nervio", el periódico "Reconstruir" y la revista "Estudios" de España, entre otras. En relación con esta última, Isabel Jiménez-Lucena y Jorge Molero-Mesa han comprobado, a su vez, el diálogo transatlántico que se alimentó a partir de las notas de Lazarte en la publicación ibérica. ${ }^{7}$

En esas décadas, descuidadas por la historiografía local del anarquismo, ${ }^{8}$ y signadas por el auge de la producción editorial nacional, ${ }^{9}$ se dieron numerosos emprendimientos que no se circunscriben a este movimiento, pero que tenían muchos de sus voceros en sus índices. En ese marco, la investigación de Ledesma Prietto confirmó que, pasado el auge de las primeras décadas del siglo, la experiencia anarquista continuó tallando en el debate sobre lo sexual principalmente, a través de revistas culturales y emprendimientos editoriales vinculados a las izquierdas en sentido amplio. Sin embargo, ese recorte estratégico para los objetivos de aquel trabajo, dejó de lado otras zonas de la prensa

\footnotetext{
${ }^{4}$ Nadia Ledesma Prietto, Eugenesia y revolución sexual: El discurso médico anarquista sobre el control de la natalidad, la maternidad y el placer sexual. Argentina, 1931-1951. Tesis de Doctorado. Facultad de Humanidades y Ciencias de la Educación, Universidad Nacional de La Plata, Buenos Aires, Argentina, 2014.

${ }^{5}$ Nadia Ledesma Prietto, "Una genealogía anarquista de la Sexología. Argentina, 1930-1950. Apuntes para su estudio", Jornadas de intercambio del Programa de investigación del Anarquismo (CeDInCI/UNSAM), Buenos Aires, octubre 2018.

${ }^{6}$ Richard Cleminson, Anarquismo y sexualidad en España (1900-1939), Cádiz, Universidad de Cádiz, 2008.

${ }^{7}$ Isabel Jiménez-Lucena y Jorge Molero-Mesa, "Una dialógica desestabilizadora del orden social y sexual: el médico argentino Juan Lazarte en la revista anarquista Estudios (1932-1936)", Asclepio, Vol. 66, n 2, $2014,0-56$.

8 Agustín Nieto, "Notas críticas en torno al sentido común historiográfico sobre 'el anarquismo argentino"”, $A$ Contracorriente. Revista de Historia Social y Literatura en América Latina, $\mathrm{n}^{\circ}$ 3, 2010, 219-248.

${ }^{9}$ José Luis de Diego, (dir.) Editores y políticas editoriales en Argentina, 1880-2000, Buenos Aires, FCE, 2006.
} 
anarquista tales como su principal periódico, "La Protesta", o periódicos de los sectores que acometieron un fuerte proceso de reorganización tras el primer golpe de Estado en el país.

Es necesario, por tanto, profundizar la línea de investigación relacionada con la sexualidad, tal como propone Cleminson, y explorar otras zonas del anarquismo que todavía no han sido alcanzadas desde este tipo de interrogaciones. El presente artículo se propone avanzar sobre esa suerte de vacancia a partir de las orientaciones teóricas de la obra de Michel Foucault en relación con la historia de la sexualidad. ${ }^{10}$ Su idea central acerca de la profusión de discursividad en torno al sexo en contra de la clásica "hipótesis represiva", no solo fue señalada como pertinente para analizar el caso del anarquismo en el libro señero de Barrancos, sino que continua siendo eficaz para dar cuenta de esa intensa producción y, sobre todo, para evitar análisis reduccionistas. Así, los discursos sobre la cuestión sexual desde el anarquismo dejan de pensarse como un hecho singular y, sobre todo, como un conjunto monolítico. Al contrario, los lineamientos metodológicos que sostienen esta investigación, construidos a partir de la obra colectiva y fragmentaria de Mijail Bajtín - apuntan a describir "el concierto de la prensa anarquista" como un terreno heterogéneo, atravesado por los debates y permeado por discursos que no necesariamente provenían de un ideario original o cerrado. ${ }^{11}$ Ese concierto de voces se expresaba en distintos tipos de publicaciones tales como folletos, libros y periódicos, por tanto, para comprender con mayor profundidad el compromiso anarquista con la cuestión sexual es preciso atender a todo ese abanico de producciones.

Esta indagación parte de una hipótesis según la cual afirmamos que, mientras las publicaciones culturales y los proyectos editoriales anarquistas (o con protagonismo anarquista) se abocaron a la difusión de saberes relacionados con la cuestión sexual, los sectores más comprometidos con una reorganización orgánica y federal del anarquismo, y con una fuerte opción por una estrategia sindical, dieron menos espacio y profundidad en sus periódicos a esa problemática. Con la salvedad de uno de los elementos menos controvertidos del ideario: la "emancipación de la mujer".

La comprobación de esta hipótesis de carácter general sólo puede darse por etapas, de modo que el objetivo central del artículo será someterla a una primera prueba sobre el periódico "Acción libertaria", órgano de expresión del Comité Regional de Relaciones Anarquistas (CRRA), de la Federación Anarco Comunista de la Argentina (FACA) y, más tarde, de la Federación Libertaria Argentina. El periódico se sostuvo entre los años 1933 y 1971, pero tuvo un corte significativo hacia fines del gobierno de Juan Domingo Perón, lo cual justifica una selección que parte desde el primer número (septiembre de 1933) hasta 1955, año en el que el periódico se recupera y se orienta hacia el contexto de grandes cambios que abre la caída del peronismo.

El artículo se divide en una introducción, tres apartados analíticos y una conclusión. El primer apartado ofrece un breve paneo del desarrollo del anarquismo en la Argentina hasta los años treinta cuando se publica AL. Allí se describe el periódico y se da cuenta de las investigaciones que lo abordaron previamente. El segundo apartado se detiene en la primera década de existencia de la publicación y, de manera puntual, en la comprobación

\footnotetext{
${ }^{10}$ Michel Foucault, Historia de la sexualidad (Vol. I), Buenos Aires, Siglo XXI editores, 2014.

${ }_{11}$ Laura Fernández Cordero, "Un ejercicio de lectura sobre el concierto de la prensa anarquista a partir de M. Bajtin (Argentina 1895-1925)”, AdVersuS. Revista de Semiótica, n² 24, Buenos Aires, 2013, 69-91.
} 
de la hipótesis propuesta. Ese tipo de análisis de la fuente que la hipótesis requiere continúa en el tercer apartado en el marco de la relación del periódico con los gobiernos de Juan Domingo Perón, con acento en la figura femenina central del momento, Eva Duarte de Perón. Finalmente, las conclusiones recuperan el conjunto de las argumentaciones y proyectan interrogantes hacia futuras elaboraciones que pongan en diálogo AL con otras publicaciones del período.

\section{El periódico Acción libertaria como vocero del anarquismo}

Los primeros indicios de actividad anarquista en la región se dan en las últimas tres décadas del siglo XIX cuando arriban al Río de la Plata, tanto quienes eran expulsados de Europa por sus actividades revolucionarias, como quienes buscaban llevar sus ideas a otras regiones con claros objetivos de internacionalización. A partir de este movimiento heterogéneo conformado por inmigrantes de distintas zonas de España, Italia, Bélgica y Francia se fueron organizando diversos grupos entre los que se destacaron quienes se nucleaban en torno a Errico Malatesta, militante italiano que vivió en Buenos Aires entre 1885 y 1889. Comprometidos con el comunismo anárquico, fundaron el periódico "La Questione Sociale" (1885-1886). Durante los años posteriores, se verifica la presencia de una corriente individualista expresada por periódicos como “El Perseguido" (1890-1897), "La Anarquía" (1895-1898), “Germinal" (1897-1898) y “El Rebelde" (1898-1903), sin embargo, hacia los primeros años del siglo siguiente se consolida la corriente ligada al anarquismo de corte organizador que impulsa unas de los principales publicaciones del movimiento: "La Protesta Humana" (1897), periódico que luego asume el nombre "La Protesta" (1903) y atraviesa todo el siglo.

Por la fuerte presencia del anarquismo en el incipiente movimiento obrero y su protagonismo en las huelgas este período es el que concentra la mayor parte de los estudios historiográficos, 12 así podemos seguir de cerca las vicisitudes de la represión que sufrieron por parte del Estado a partir de la Ley de Residencia de 1902 y la Ley de Defensa Social de 1910. A pesar de las persecuciones, el anarquismo llegó a liderar la primera federación obrera (FOA) y la posterior Federación Obrera Regional Argentina (FORA). Diversos cambios en la vida económica, social y política del país explican el repliegue del movimiento, a pesar de que tallaron en acontecimientos puntuales como las huelgas en los talleres Vasena, hacia fines de 1918, jornadas conocidas como "la Semana Trágica". La década del veinte estuvo signada por un alto nivel de conflictividad interna y la renovación del debate en numerosas publicaciones, 13 entre otras: "La Protesta", "La Antorcha", "La Palestra" (1924- 1929), "El Libertario" (1923-1932) y “Vía Libre" (1919-1922) de Buenos Aires, "Ideas" (1921-1925) de La Plata, "Pampa Libre" (1922-1930) de General Pico,

\footnotetext{
${ }_{12}$ Diego Abad de Santillán, El movimiento anarquista en la Argentina desde sus comienzos hasta 1910, Buenos Aires, Argonauta, 1930. Iaacov Oved, El anarquismo y el movimiento obrero en Argentina, México, Siglo XXI, 1978. Gonzalo Zaragoza, Anarquismo argentino (1876-1902), Madrid, De la Torre, 1996. Juan Suriano, Auge y caída del anarquismo. Argentina, 1880-1930, Buenos Aires, Capital Intelectual, 2005.

${ }^{13}$ Luciana Anapios, El movimiento anarquista en Buenos Aires durante el período de entreguerras, Tesis doctoral, Facultad de Filosofía y Letras, Universidad de Buenos Aires, 2012.
} 
"Adelante" (1922-1927) de Tucumán, "Brazo y Cerebro" (1922-1930) de Pergamino y "Voluntad" (1924) de Mar del Plata.

Como en el resto de las izquierdas, la prensa tuvo un papel sustancial para el anarquismo. Trabajos como los de Juan Suriano y Luciana Anapios demuestran su multiplicidad y dinamismo a lo largo de las primeras décadas del siglo XX. ${ }^{14}$ En un artículo previo, una serie de tesis bajtinianas nos permitía dar cuenta de la importancia de esa proliferación de publicaciones ya que distinguíamos, como una característica propia del anarquismo, la puesta prueba constante del ideario a través de polémicas y debates que tenían por soporte revistas y periódicos. ${ }^{15}$

La prensa periódica posterior a los años treinta ha sido menos frecuentada en términos de conjunto, no contamos para ese espacio de producción estudios como los que destinaron Osvaldo Graciano y Lucas Domínguez Rubio a los proyectos editoriales del anarquismo. ${ }^{16}$ Todavía es preciso descubrir periódicos y revistas de otras ciudades que circulaban a la par de los capitalinos, y que se editaban con mucho esfuerzo en un período particularmente turbulento inaugurado por el golpe de Estado que encabezó el general José Félix Uriburu el 6 de septiembre de 1930. A partir de allí, la represión se intensificó y sacudió al movimiento obrero y, en especial, al anarquismo que mantuvo, pese a todo, cierta fortaleza en los frentes sindical y cultural. ${ }^{17}$ Aunque afectado por la persecución y por los cambios económicos y políticos que explican, en parte, la disminución de su capacidad de orientación de los sectores obreros, el anarquismo acometió un proceso de reorganización que tuvo entre sus pilares al Comité Regional de Relaciones Anarquistas (CRRA). Esta experiencia organizativa - analizada en extenso en el trabajo de Fernando López Trujillo 18 tuvo su puntapié inicial en plena situación de encarcelamiento cuando un grupo nutrido de militantes puso en marcha el proceso que dio lugar al Segundo Congreso Anarquista Regional de la República Argentina, celebrado en la ciudad de Rosario en 1932. Tres años después, tomará forma la Federación Anarco Comunista Argentina (FACA) que se convertirá, ya en 1955, en la Federación Libertaria Argentina. Durante casi cuatro décadas, el principal órgano de expresión de ese sector del anarquismo fue el periódico "Acción Libertaria” (en adelante AL), cuyo primer número apareció en septiembre de 1933.

Contamos con productivos acercamientos puntuales a AL. Agustín Nieto rastreó, para su tesis doctoral, huellas de una sostenida militancia sindical en todo el país. ${ }^{19}$ Por su

\footnotetext{
${ }^{14}$ Juan Suriano, Anarquistas. Cultura y política libertaria en Buenos Aires, 1890-1910, Buenos Aires, Manantial, 2001. Luciana Anapios, op. cit.

${ }^{15}$ Laura Fernández Cordero, 2013, op.cit.

${ }^{16}$ Osvaldo Graciano, "La escritura de la realidad. Un análisis de la tarea editorial y del trabajo intelectual del Anarquismo argentino, entre los años 30 y el Peronismo", Izquierdas, Santiago de Chile, 2012, 72-110. Lucas Domínguez Rubio, "Un itinerario por los proyectos editoriales del anarquismo en Argentina: cambios, maniobras y permanencias", Izquierdas, $\mathrm{n}^{\mathbf{0}}$ 33, 2017, 21-41.

${ }^{17}$ Agustín Nieto, "Entre anarquistas y peronistas. Organización sindical y experiencias obreras en la industria del pescado, Mar del Plata, 1942-1966", Tesis doctoral, Universidad Nacional de Mar del Plata, 2012. Pablo Pérez, Juan Manuel Heredia y Hernán Villasenin, "El trabajo cultural del anarquismo. La Biblioteca Archivo de Estudios Libertarios de Buenos Aires (1995-2005) y el Instituto de Documentación Social CNT-FAI (1938)", Germinal: revista de estudios libertarios, $\mathrm{n}^{\circ}$ 2, 2006, 107-125.

${ }^{18}$ Fernando López Trujillo, Vidas en rojo y negro. Una historia del anarquismo en la "Década Infame”, La Plata, Letra Libre, 2005.

${ }^{19}$ Agustín Nieto, op. cit.
} 
parte, Diego Ceruso relevó el trabajo sindical de base y lo comparó con la Alianza Obrera Spartacus, otra agrupación que actuó en la primera parte de la década del treinta. ${ }^{20}$ En relación con las luchas antifascistas, María Eugenia Bordagaray encontró un compromiso particular del periódico, visibilizó la solidaridad hacia los acontecimientos revolucionarios en España, y relevó el impacto de los gobiernos de Juan Domingo Perón. ${ }^{21}$ Retomaremos este último aspecto más adelante, junto al trabajo de Alejandra Gómez dedicado a la recepción del fenómeno peronista en AL.22

Es posible que un obstáculo para el estudio en profundidad de AL resulte de la inexistencia de una colección completa del periódico. Los ejemplares preservados se encuentran en distintos repositorios, y esta dispersión obliga a una labor de recopilación que sólo puede obtener buenos resultados si se acomete de manera colectiva, tal como hicimos para este trabajo. ${ }^{23}$ Así logramos armar una serie que, aunque con algunos faltantes, permite apreciar la existencia de una publicación sostenida que pretende mantener una frecuencia mensual o bimestral, pero que no siempre llega a cumplirlo a causa de las censuras, la persecución policial o las vicisitudes económicas. El periódico lleva el mismo título que el célebre portavoz de la Confederación Nacional del Trabajo (CNT) de España en los años veinte. Expresa la voz del Comité Regional de Relaciones Anarquistas (CRRA), de la Federación Anarco Comunista de la Argentina, después, y de la posterior Federación Libertaria Argentina; sus subtítulos varían a lo largo de las décadas, al calor de los cambios en la propia organización.

El tamaño y la frecuencia (bimestral, mensual, quincenal) también se alteran a través de los años, así como la cantidad de páginas, aunque mantiene un promedio de 4 hojas, en blanco y negro (salvo alguna excepción de títulos de tapa rojos), con ejemplares que duplican esa cantidad. No hay datos fehacientes sobre la tirada del periódico. AL no contiene publicidades, mantiene un precio de venta bajo y recurre a las suscripciones de la militancia. En cuanto a la dirección, recién hacia 1958 comienza a aparecer el nombre de Raimundo Díaz, responsable a quien se dirige la correspondencia. Continuará a cargo de la publicación hasta el momento de su muerte, en agosto de 1967, y lo sucederá Antonio J. Cora. Entre sus principales colaboradores se cuentan: Jacobo Prince, Jacobo Maguid, Fernando Quesada, Gaston Leval, Luis Danussi, Diego Abad de Santillán, Enrique Palazzo, Jorge Ballesteros, Ciriaco Duarte, Osmar Suárez, Juan Pérez, y Horacio Roqué. A lo largo de los años no se observan secciones fijas, salvo algunos títulos destacados que se repiten como "Juventud anarquista", "Juventudes libertarias", "Noticias del mundo obrero" o

\footnotetext{
${ }^{20}$ Diego Ceruso, "El trabajo sindical de base del anarquismo argentino: la FACA y la Alianza Obrera Spartacus", A Contracorriente: una revista de estudios latinoamericanos, $\mathrm{n}^{\circ} 3,2011,233-254$

${ }^{21}$ María Eugenia Bordagaray, "Controversias libertarias: La interpelación anarquista en tiempos del peronismo", Tesis doctoral, Facultad de Humanidades y Ciencias de la Educación, Universidad Nacional de La Plata, 2014. "Luchas antifascistas y trayectorias generizadas en el movimiento libertario argentino (1936-1955)", Cuadernos de H Ideas, nº 7, Universidad Nacional de La Plata, 2013.

22 Alejandra Gómez, "Recepción del fenómeno peronista desde el anarquismo argentino: la FACA y su posicionamiento político ideológico en torno a la cuestión agraria y el problema campesino` durante los dos primeros gobiernos peronistas (Argentina, 1946-1955)", inédito.

${ }^{23}$ Es posible consultar AL en: Centro de Documentación e Investigación de la Cultura de Izquierdas (Buenos Aires), Biblioteca Popular José Ingenieros (Buenos Aires), Biblioteca Alberto Ghiraldo (Rosario) y Biblioteca Juventud Moderna (Mar del Plata). La compilación fue posible gracias a la colaboración generosa de Lucas Domínguez Rubio, Ivanna Margarucci, Agustín Nieto y Tomás Verbrugghe.
} 
"Problemas del mundo obrero". Otras secciones se sostienen unos pocos números como "Contrafilo", "Con las manos en la masa", "A dónde va el mundo" o "Resumiendo" que constituyen espacios de noticias comentadas o síntesis temáticas. En la primera década cada página ofrece alguna fotografía o ilustración, luego van siendo cada vez más escasas hasta imponerse un diseño de columnas y cuadros muy abigarrados.

A través de las décadas, los temas predominantes en AL serán la propia organización del movimiento, las noticias del mundo sindical, la política nacional, el contexto internacional, las críticas al proceso ruso, el papel de la juventud, las noticias del mundo sindical, el fascismo, etc. Además, responde a cada coyuntura con especial atención en momentos candentes nacionales e internacionales como el ascenso del nazismo, la revolución española (donde la FACA tuvo un papel predominante), la guerra en Europa, los gobiernos de Juan Domingo Perón, la revolución en Cuba, etc.

Salvo Bordagaray, quien recuperó el protagonismo de la mujer en la organización de ayuda y sostenimiento de la lucha en España, ninguno de los trabajos previos aquí señalados ha explorado AL desde algún otro aspecto de la cuestión sexual. Es por eso que someteremos a prueba la hipótesis ya anunciada con el fin de comenzar a confirmar que la prensa orgánica de los sectores más comprometidos con una reorganización federal del anarquismo, y con una fuerte opción por una estrategia sindical, muestran menos interés en esa problemática, sin abandonar la noción de la "emancipación de la mujer", central en el ideario anarquista. Con ese objetivo, analizaremos las primeras dos décadas de edición, específicamente, desde su aparición en septiembre de 1933 hasta 1955, año en el que el periódico se recupera de una fuerte discontinuidad, y se orienta hacia el contexto de grandes cambios que dispone la caída del peronismo.

\section{La cuestión sexual en la primera década de Acción libertaria}

La expresión "cuestión sexual" no tiene un uso frecuente en la discursividad anarquista, sin embargo, una traducción del libro de Auguste Forel "La question sexuelle. Exposée aux adultes cultivés" (1906) tenía mucha circulación y varias ediciones en castellano producidas en Buenos Aires. Si proponemos utilizarla es por su cualidad sintética ya que nos permite englobar un conjunto de argumentaciones relacionadas con la emancipación de la mujer, el ejercicio de la sexualidad, la reproducción y la anticoncepción, la homosexualidad, la moral sexual, y la salud y las enfermedades ligadas a lo sexual, entre otras. El anarquismo fue el más adelantado en su tiempo en relación con su vocación de relacionar esos aspectos con la Revolución Social, sin embargo, la cuestión sexual formaba parte del proyecto político y cultural de todo el arco de izquierdas locales, gran parte de cuya producción editorial estuvo dedicada a ese aspecto de la transformación social.24 Dentro del mundo libertario es posible hacer una caracterización general en términos de contenido, sin olvidar que la discursividad anarquista no resiste una interpretación homogeneizadora, tal como advierte Cleminson en el trabajo ya citado. Las argumentaciones más sostenidas en las publicaciones del período incluían una explícita oposición al matrimonio tradicional y al mandato católico y religioso en general. Se proponía una distinción tajante entre la práctica sexual y la procreación, junto al fomento

\footnotetext{
${ }^{24}$ Fernández Cordero, 2014, op. cit; Ledesma Prietto, 2016, op. cit.
} 
de distintos medios de control de los embarazos y de un ejercicio controlado de la sexualidad, generalmente orientado por la salud física y la integridad moral en un marco heterosexual. La homosexualidad adquirió mayor presencia como temática y sería discutida en términos médicos y morales. La mirada científica se imponía sobre otras perspectivas con una gravitación decisiva de las argumentaciones provenientes de la medicina y de la psicología.

Con el objetivo de poner a prueba nuestra hipótesis acerca de la presencia de este conjunto de tópicos en la prensa ligada a este sector particular del anarquismo, realizamos un rastreo exhaustivo en las páginas de AL durante sus primeros diez años de edición. Como primer resultado debemos consignar una ausencia evidente: las relaciones afectivas y sexuales no son objeto de notas doctrinarias ni de opinión, ni ocupa a las plumas más destacadas de la redacción como ocurría con frecuencia en los principales periódicos del movimiento en las primeras dos décadas del siglo XX. En cambio, un segundo repaso detenido sugiere que esa ausencia no es completa ya que la emancipación de la mujer, idea muy cara al movimiento, se presenta de distintas maneras a lo largo del periódico.

Las argumentaciones relacionadas con este tópico son muy estables y se repiten en la prensa anarquista local desde fines del siglo XIX. De hecho, dos de los primeros folletos editado por el anarquismo en el país se titularon "La Mujer" y "La mujer y la familia" (Emilio Z. Arana). Como otros movimientos emancipatorios, se proponía la liberación de la mujer de yugos varios que iban desde la explotación económica generalizada a una opresión específica que hacía de las mujeres las "esclavas entre los esclavos". Los trabajos de Molyneux, Bellucci y otros ya citados problematizan ese punto de partida, convocando "la voz de la mujer" que, a través de periódicos escritos y dirigidos por ellas, discutieron las limitaciones de la mentada liberación. ${ }^{25}$ Las mujeres resistieron las aristas paternalistas de la convocatoria que los hombres anarquistas hacían para promocionar la participación femenina en la lucha, y produjeron sus propios periódicos a fin de potenciar su mensaje, dado que encontraban poco espacio en las publicaciones dirigidas por los compañeros.

En el caso de AL, las firmas femeninas son casi inexistentes, salvo algunas plumas célebres como las de Federica Montseny y Luce Fabbri. Montseny es una de las voces femeninas más reconocidas, por ejemplo, en una nota de primera página, la escritora se dirige a las Américas con una prosa altamente emocional para rogar solidaridad con España. Les habla como "mujer y madre", les pide "movilizad vuestras conciencias", y apela a su "sentimiento maternal". ${ }^{26}$ Este tipo de discurso mantiene una fuerte continuidad con el maternalismo, omnipresente en las enunciaciones anarquistas de todo el siglo. Meses más tarde, apenas unas líneas recuerdan a Soledad Gustavo, escritora y célebre militante con presencia en periódicos y folletos locales desde fines del siglo XIX y madre de Federica. ${ }^{27}$ Mientras que, ante la muerte de Emma Goldman, se hace un elogioso recordatorio en tanto "gran compañera e infatigable luchadora". La nota rememora su formación ideológica, su recorrido por diversos países y varias de sus consecuentes intervenciones, sin embargo, no se dedica ni una línea a evocar su compromiso con la

\footnotetext{
25 "La Voz de la Mujer" (1896-1897) y "Nuestra Tribuna" (1922-1925)

${ }^{26} \mathrm{AL}, \mathrm{n}^{\circ} 31,4 / 1938,1$

${ }^{27} \mathrm{AL}, \mathrm{n}^{\circ} 34,3 / 1939,4$
} 


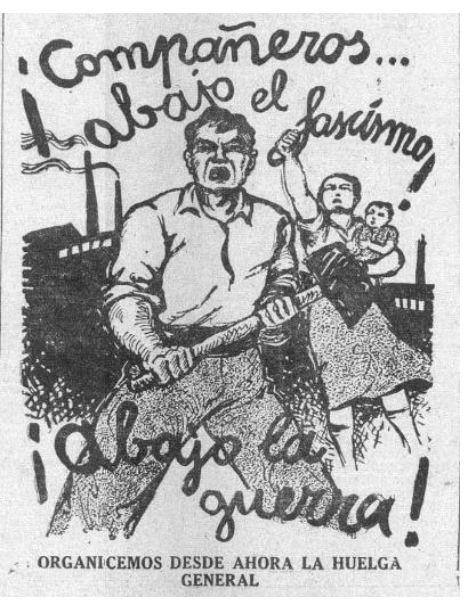

emancipación de la mujer, la promoción del amor libre o los métodos de anticoncepción. ${ }^{28}$ Ya en 1941, Federica Montseny toma la primera plana con una biografía laudatoria y una importante fotografía porque llegan indicios de su posible fallecimiento. Aunque meses más tarde hay noticias de que se encontraba con vida, intentando dejar España y corriendo el riesgo de ser entregada a Francisco Franco. ${ }^{29}$

Fig. 1.

Sin notas centrales, ni firmas femeninas que propicien la polifonía a la que nuestro marco metodológico dirige la atención, es preciso recurrir a otras zonas del periódico que ofrecen indicios sobre la dimensión analizada. Es el caso de las ilustraciones, frecuentemente olvidadas en los análisis sobre la prensa. Así, podemos observar el cariz paternalista mencionado en una imagen que ofrece a la mujer el lugar de acompañante, detrás del hombre; ella anima la lucha masculina, mientras se encarga de la crianza [Fig.1]. ${ }^{30}$

Muchas de las imágenes seleccionadas para acompañar las notas demuestran una alta valoración de la mujer española combatiente. Mujeres armadas, con pose militar o apostadas en las trincheras se suceden al ritmo de la revolución en la península [Fig. 3 y 4]. ${ }^{31}$

Fig. 3

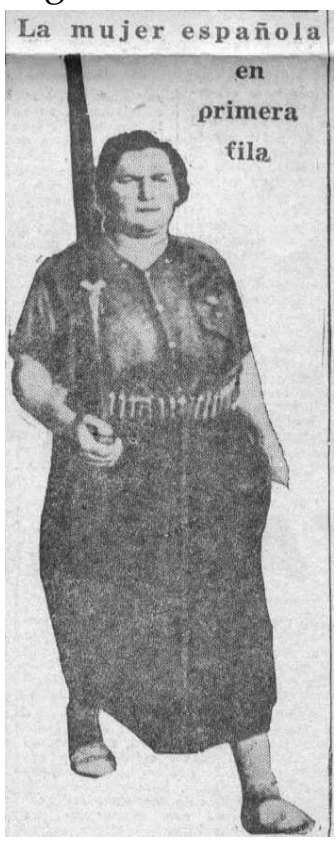

Fig. 4

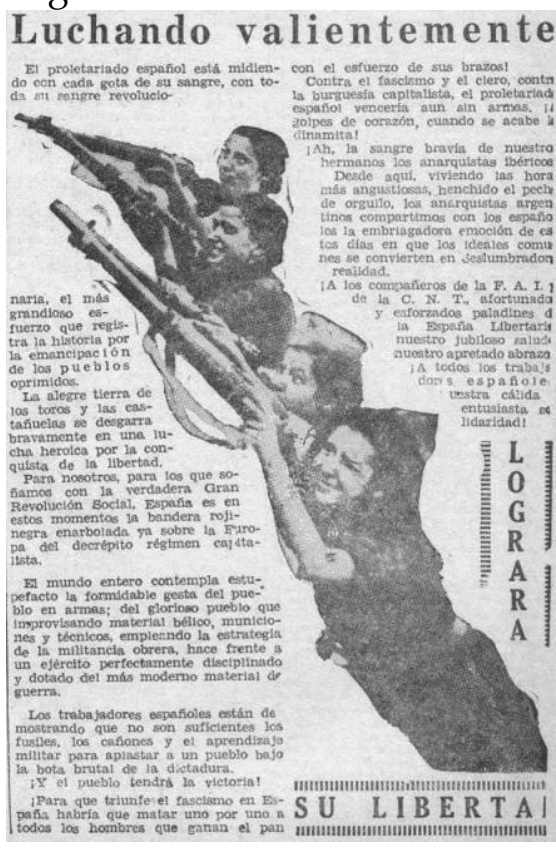

${ }^{28} \mathrm{AL}, \mathrm{n}^{\mathrm{o}} 37,6 / 1940,3$

${ }^{29} \mathrm{AL}, \mathrm{n}^{\circ} 50,11 / 1941,1$

${ }^{30} \mathrm{AL}, \mathrm{n}^{\circ} 16,12 / 1935,1$

${ }^{31}$ AL, no 20, 8/1936, 1 y 4 
Para comprender los matices de la propuesta de liberación de las mujeres, es preciso analizarla en diálogo con las construcciones sobre lo masculino. Así vemos que la imagen de un puño alzado refuerza con el título la idea de que el ímpetu y el talante combativo son características masculinas. Como se sabe, era común en la época caracterizar como "viril" la pluma o la oratoria que expresara convicciones firmes, incluso aunque las asumiera una mujer [Fig.2]. ${ }^{32}$

En otra nota, el manifiesto repudio de la "Asociación estudiantil libertaria" a la visita del Gregorio Marañón, reconocido médico e intelectual español, condensa sentidos sobre lo masculino, lo femenino y, en especial, sobre la relación entre virilidad heterosexual y lucha:

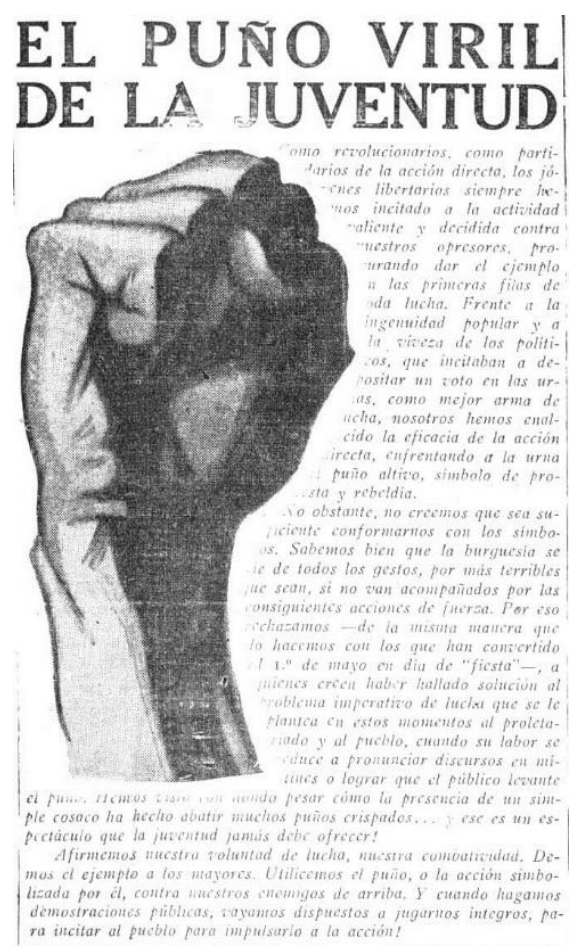

Fig. 2

Al sabio Marañón lo buscaremos en sus libros y recogeremos sus enseñanzas. El que ahora viene a nosotros es su caricatura y su negación. Es el médico de ricos, el consolador de niñas histéricas, el ateneísta mariconeador de conceptos, el intelectual sin decoro y sin dignidad, que viene a justificar su lamentable miedo y a ocultar su vergüenza de traidor. Que nuestro índice inexorable lo señale y nuestro repudio lo hunda sin apelación. ${ }^{33}$

Al momento de analizar la centralidad de algunas temáticas en la organización de este sector del anarquismo es importante revisar las declaraciones, manifiestos e informes de las organizaciones federales o internacionales. Allí podemos comprobar que no hay signos de la cuestión sexual en conjunto, pero se confirma la importancia de la problemática femenina. Por caso, un folleto de la FACA titulado "Tu organización, Compañero" presenta una "exposición sintética" de los puntos de vista de la Federación podemos ver que, entre los elementos constantes como la Libertad, la crítica al Estado, el racismo y el antimilitarismo, se registra el tema de "la mujer en la lucha social".

En el mismo número, una nota firmada por Américo NUEVO nos permite comparar ese temario con uno de 1898, año en el que se funda una pionera Federación Libertaria. En la transcripción de la declaración de principios de aquella primera federación, que el autor reconoce como un antecedente virtuoso, ocupaba un tercer lugar la denuncia de la "mentira matrimonial" y la propuesta de "unión libre", inmediatamente detrás de la crítica al Estado y antes del repudio al patriotismo y al clericalismo que tomaban el cuarto y el quinto lugar. 34 Es decir, si a principios de siglo se incluía en la declaración de principios de una federación,

\footnotetext{
${ }^{32} \mathrm{AL}, \mathrm{n}^{\circ} 19,4 / 1936,3$

${ }^{33} \mathrm{AL}, \mathrm{n}^{\circ} 26,4 / 1937,1$

${ }^{34} \mathrm{AL}, \mathrm{n}^{\circ}$ 63, 3/1943, 2
} 
los ítems principales de la cuestión sexual, para el anarquismo que se expresa en AL, apenas constituye un antecedente recordable.

La estabilidad argumentativa sobre el tema de la mujer se confirma con una nota que repite, sin modificación alguna, un argumento ya presente a fines del siglo XIX cuando los hombres procuraban atraerlas. Sin firma, un enunciador masculino lamenta que, pese a la cantidad de argumentos vertidos, "la mujer" permanece ajena a la lucha. Al contrario, afirma, continúa tomada por la religión, la moda y el cine que le ofrecen valores conservadores y falsamente igualitaristas. Quien escribe, después de criticar la inconstancia y la volubilidad femenina, propone a los hombres una autocrítica ya que no saben estimularlas o apreciarlas cuando ellas se acercan, al tiempo que los exhorta a "ganar a la mujer para la lucha social" tanto en las fábricas como en los hogares. ${ }^{35}$

Estas argumentaciones se daban en un contexto nacional en el que las mujeres no tenían participación política plena, pese a que socialistas y feministas llevaban un par de décadas reclamando el derecho al voto. En términos civiles todavía había una fuerte subordinación, a pesar de algunos avances legislativos finales de los años veinte, mientras que el sentido común imperante confinaba a la mujer en su papel de esposa y madre. La creación de la FACA no estaba exenta de estas y otras tensiones presentes en el contexto político; como López Trujillo y Bordagaray enuncian, las reuniones de organización estaban atravesadas por innumerables discusiones en torno a la orientación que debía tomar la federación y los grupos que debía contener. En opinión de algunos delegados era necesario mantener una línea de oposición al capitalismo que no se desviara en frentes que consideraban casi accesorios. Sin embargo, pese a las resistencias, los colectivos de mujeres, estudiantes y militantes contra la guerra pasaron a formar parte del proceso de reorganización del anarquismo, y las páginas de AL lo constatan.

En suma, luego de recorrer los primeros diez años del periódico AL podemos postular la validez parcial nuestra hipótesis según la cual la cuestión sexual no constituye una problemática de importancia en el órgano que da voz al anarquismo comprometido con la organización federal del movimiento y la intervención en el frente sindical. Sin embargo, las notas analizadas dan cuenta de una presencia sostenida y homogénea sobre el tema de la emancipación de la mujer.

\section{El periódico durante los gobiernos de Juan Domingo Perón}

Tras una convulsionada década, un nuevo golpe de Estado sacude al país en junio de 1943. Ese proceso y las grandes movilizaciones populares del 17 de octubre de 1945 explican, en parte, el nacimiento de un nuevo movimiento que tendrá como líder a Juan Domingo Perón. En las sucesivas ediciones de AL podemos observar que las críticas que venía despertando el proceso que culminaría con el primer gobierno de Perón, en 1946, se fueron intensificando a medida que el peronismo se consolidaba como fuerza política. Alejandra Gómez dio cuenta de la recepción del peronismo en la FACA explorando con atención las páginas del periódico y comprobó que la oposición de este sector del anarquismo era contundente. Deploraban lo que consideración una injusta apropiación que el peronismo habría operado sobre las luchas obreras previas y, en forma general,

${ }^{35} \mathrm{AL}, \mathrm{n}^{\mathrm{o}} 33,5 / 1938,6$ 
denunciaban la orientación que el movimiento obrero y el sindicalismo tomarían en su fuerte vinculación con un Estado fortalecido. A su vez, el trabajo de María Eugenia Bordagaray señala que la posición antifacista que abrazó el anarquismo (junto a otras expresiones de izquierda) alimentó su explícito antiperonismo y le permitió forjar alianzas con otros sectores opositores. Las notas, muy críticas, se centraban en temas como el avance sobre el movimiento obrero, el estatismo creciente, el liderazgo desmedido de su figura central, el militarismo, la cercanía a los fascismos europeos y casi cualquier acción que emprendiera el gobierno. Al mismo tiempo, el periódico sufría de manera directa por las "restricciones a la libertad de prensa" y por las dificultades propias de una publicación en un contexto político adverso, lo cual provocó algunas discontinuidades en su edición. El accionar represivo de la policía y la tortura sobre los detenidos fueron denunciados de manera constante, con particular acento en los casos que involucraban mujeres como víctimas.

Tal como propusimos para el período anterior, recorrimos estos 12 años de AL con el fin de someter a prueba la hipótesis que guía este trabajo. Una primera mirada sobre las temáticas que ocupan al periódico evidencia que no está entre ellas lo que denominamos cuestión sexual. Si revisamos las comunicaciones e informes de reuniones y congresos nacionales o internacionales comprobamos nuevamente esa ausencia. En 1952 un importante congreso de la FACA nos da la oportunidad de sopesar los elementos que vertebraban el movimiento por esos años y corroborar que, al igual que en su primera década, se mantiene el tópico de la emancipación de la mujer. Una síntesis del congreso presenta, en recuadro destacado, un "Acuerdo sobre la participación de la mujer en la lucha social". El diagnóstico es similar tanto a los primeros años de AL como a las primeras décadas del siglo: la participación de la mujer es escasa y "poco orgánica". Si entre las razones de aquellos tiempos se contaba el lastre de la religión, ahora se acusará al gobierno peronista con su "obsequio" inaceptable del voto femenino. Se acuerda, de manera urgente, realizar intensas campañas, procurar espacios de formación y, en particular:

Propiciar trabajos afines a la sensibilidad de la mujer, tales como visitar presos, llevar colaboración a los hogares víctimas de la saña oficial, vigilar la instrucción de la infancia en las escuelas tratando de liberarlas de la influencia perturbadora de la iglesia y la política en las aulas, etc. [...]Facilitar por todos los medios, la capacitación teórica y práctica de la mujer para trabajos de mayor envergadura en bien de una futura y próxima transformación social que traiga sobre este mundo de desolación y lágrimas, más justicia, más paz y más amor. ${ }^{36}$

De esta cita se desprenden algunos elementos significativos: no surgen nombres o figuras de mujeres en actividad que puedan llevar adelante estas acciones hacia sus congéneres, se sostiene el viejo argumento de la falta de educación y capacitación femenina, se posterga su protagonismo a un futuro en el que la mujer lograría una participación destacada y, por último, se la circunscribe a ciertas tareas consideradas propias de la condición de su género relacionadas con el cuidado, el ámbito familiar o el sostén emocional.

${ }^{36} \mathrm{AL}, \mathrm{n}^{\mathrm{o}} 136,6 / 1952,5$

Modalidad de publicación continua / Continuous publication modality 
A causa de que la situación política obligara a suprimir firmas en la mayoría de las notas, es difícil sopesar el espacio que tenían las escrituras femeninas. Sin embargo, una nota a doble página que recupera nombres propios, caros al movimiento local e internacional, no destaca a ninguna mujer, a pesar de que había muchas mujeres con plena participación, tal como sabemos gracias a los aportes de Ledesma Prietto y Bordagaray. El papel secundario y el ninguneo que los discursos masculinos terminaban por dispensarle a las compañeras, pese al mandato doctrinario, fue denunciado varias veces por las anarquistas. Entre los casos emblemáticos se cuentan sendos periódicos que fueron producidos y sostenidos por ellas. Primero, las redactoras del periódico "La Voz de la Mujer" (1896-1897) quienes fueron llamativamente apodadas las "feroces de lengua y pluma" por sus propios compañeros. Más tarde, las responsables de "Nuestra Tribuna" (1922-1925) quienes, con Juana Rouco a la cabeza, editaron 39 números en los cuales logran demostrar que, más que secundar, protagonizan la lucha social y procuran imprimir en ella sus propias reivindicaciones. Sin embargo, esas voces pertenecen a otro momento histórico en el cual el "concierto de la prensa anarquista", tal como lo llamaban, era mucho más diverso y polifónico. En cambio, si bien la actividad continúa en los años que nos ocupan, la prensa es más limitada y las posibilidades de leer el posicionamiento de las mujeres se restringe a unas pocas notas o a páginas acotadas como es el caso de la "La página de la mujer" del periódico "Reconstruir", expresión del socialismo libertario. ${ }^{37}$

En relación con la problemática que aborda este artículo es significativo realizar un contrapunto con el tratamiento que se dispensaba a Eva Duarte de Perón, figura femenina dominante de la escena política por esos años. En sus ya clásicos trabajos sobre ella, Marysa Navarro ha señalado el valor carismático de su presencia en la construcción del peronismo, y las fuertes reticencias y ataques que concentraba su nombre. ${ }^{38} \mathrm{Su}$ participación fue determinante en la organización del partido, la Fundación que llevaba su nombre, y la inclusión de las mujeres en la política, tal como analizan los trabajos de Carolina Barry. ${ }^{39}$ Citar la extensa bibliografía dedicada a Eva Duarte escapa a los límites de este trabajo, por lo cual reduciremos el foco mencionando que las estrategias de Eva orientadas específicamente a las mujeres de oponían de plano a reivindicaciones de las anarquistas. Sin embargo, en AL no encontramos las opiniones de ellas sino de los compañeros que, desde un primer momento, la califican con desdén como la "señora", la "cónyuge", la "presidenta".

Una nota muy temprana, dado que estamos al comienzo del primer gobierno, ofrece un perfil cuyo título - "Descamisada sin frenos" - anticipa las caracterizaciones con que será descripta con dureza por el antiperonismo posterior: "Alguien dijo que la oposición creó a Evita Duarte, presidenta, primera dama, primera descamisada, primera samaritana, reina de la zafra y el resto por venir. La sacó de la calle donde, según confesó la señora, hace poco tuvo que ganarse la vida - sus ex colegas bien saben cómo - y la puso junto al corazón del salvador del país." 40

\footnotetext{
${ }^{37}$ Ledesma Prietto, 2014, op. cit.

${ }^{38}$ Marysa Navarro, "El liderazgo carismático de Evita", La Aljaba, La Pampa, 2001, 27-46 Evita, Buenos Aires, Editorial Planeta, 1994.

${ }^{39}$ Carolina Barry, Evita capitana: el Partido Peronista Femenino, 1949-1955. EDUNTREF, Editorial de la Universidad Nacional de Tres de Febrero, 2009.

${ }^{40} \mathrm{AL}, \mathrm{n}^{\circ}$ 96, 12/1946, 2
} 
Además de sugerir un pasado de prostitución, relacionado con su trabajo como actriz, el resto de la descripción hace hincapié en su poder sobre el líder, en su tendencia a la ostentación y en la supuesta hipocresía de sus actos en favor de los trabajadores. En consonancia, una interesante nota publicada tras su reciente muerte - bajo el título "Mística dirigida y administrada" - advierte la poderosa eficacia de la propaganda sobre las masas, lo cual se habría dado a través de una calculada campaña "idolátrica" y un estudiado efecto "martirologio". La imagen que resulta más deplorable a quien escribe es la de "las multitudes alineadas durante largas horas para contemplar por uno minuto los restos de una mujer que, después de haber llegado a la cúspide del poder - del que disfrutó con frenesí insaciable - pagó su tributo a una enfermedad que no perdona." 41

Más allá del consabido antiperonismo, la descripción de Eva como una mujer "insaciable", decidida y sin frenos ante el poder nos habla del imaginario patriarcal sobre la mujer en el espacio público. Su modo de intervenir en la política excede el papel ofrecido hasta entonces a las mujeres como actrices secundarias de la lucha masculina. Sus características personales la convierten el reverso (denostable) de la mujer anarquista deseable, cuyos atributos podemos vislumbrar en ocasión del segundo aniversario de la muerte de Iris Pavón, una libertaria de "nobles inquietudes", "espíritu amplio", "hondos sentimientos y valentía”, “animadora de campañas justicieras" y "cultora de la poesía. 42

Durante casi dos años AL dejó de salir acosado, según sus redactores, por la persecución policial y la intimidación política. Retoman en septiembre de 1955 a punto para saludar el golpe de estado que dio fin al segundo gobierno de Perón. Tras la breve, aunque intensa celebración, las críticas a las nuevas conformaciones políticas no tardaron en desplegarse. La autodenominada "Revolución Libertadora", comandada por Pedro E. Aramburu, en nada venía a respetar ni las promesas de la revolución ni las bondades de la libertad. Así, las notas del periódico retoman el tono opositor acérrimo, y durante toda la década abundan las intervenciones sobre las vicisitudes de la política nacional.

Tras la caída del peronismo comienza un nuevo período y una nueva denominación ya que nace la Federación Libertaria Argentina. En sus filas, reaparece una veterana militante, Juana Rouco, quien se mantendrá activa y cercana a este sector del anarquismo hasta su muerte. Por esos años, es posible vislumbrar cierta revitalización de las preocupaciones en torno a la cuestión sexual, en consonancia con el inicio de una transformación general de los parámetros sociales y culturales en torno a las relaciones afectivas y sexuales. Por la importancia de estos indicios dedicaremos un trabajo completo a las ediciones del periódico que llegan hasta 1971, año de la aparición de su último número.

\section{Conclusiones}

Este artículo se propuso realizar una contribución al estudio sobre la puesta en discurso de la cuestión sexual en las publicaciones del anarquismo durante las décadas del treinta, cuarenta y cincuenta, período menos atendido por la historiografía anarquista. Tras verificar que los avances en la historiografía local son incipientes y se ocupan, en especial, de revistas culturales y de los voceros ligados a la medicina, se propuso avanzar sobre otras

\footnotetext{
${ }^{41} \mathrm{AL}, \mathrm{n}^{\mathrm{o}} 137,8 / 1952,1$
}

${ }^{42}$ AL, n ${ }^{\circ} 141,10 / 1953,4$ 
publicaciones y sobre el proceso de reorganización del anarquismo durante esos años. La hipótesis que se puso a prueba afirma que, mientras que, como ha sido documentado, las publicaciones culturales y los proyectos editoriales anarquistas (o con protagonismo anarquista) se abocaron a la difusión de saberes relacionados con la cuestión sexual, los sectores más comprometidos con una reorganización orgánica y federal del anarquismo, y con una fuerte opción por una estrategia sindical, dieron menos espacio y profundidad en sus periódicos a esa problemática, con la salvedad del tópico "emancipación de la mujer".

Dado que se trataba de una hipótesis muy amplia, esta primera aproximación se abocó al periódico "Acción libertaria", órgano de expresión del anarquismo de la FACA. El análisis comenzó con algunos recortes, en principio, se acotó el recorrido de 1933 a 1955, con la justificación del cambio de contexto provocado por la caída del peronismo y las trasformaciones propias del espacio que pasó a denominarse Federación Libertaria Argentina. A su vez, indicios sobre una mayor presencia de la cuestión sexual hacia fines de los años cincuenta sugieren la necesidad de un futuro estudio específico que alcance el cierre del periódico. En cuanto a la organización del artículo, tras un apartado dedicado al anarquismo como movimiento y a $\mathrm{AL}$, un segundo tramo se centró en la primera década de AL y, un tercer apartado, prestó atención a los años de gobierno peronista. A pesar de esas distinciones analíticas, quedó demostrado que, a lo largo de sus primeros veinticinco años de existencia, la cuestión sexual no formó parte de los temas centrales que ocupaban las páginas del periódico. Sin embargo, tal como la hipótesis anunciaba, la problemática de la mujer, se registró de manera constante en ese período. Resultó, también, muy estable, el tenor de las argumentaciones con evidentes forcejeos entre el mandato doctrinal de la emancipación de la mujer y las apreciaciones sobre el modo en que debía integrarse a la lucha. Comprobamos esas tensiones tanto en las argumentaciones discursivas como en las imágenes que acompañaban las notas.

Recurrir a los periódicos animados por compañeras antecesoras, como "La Voz de la Mujer" y "Nuestra Tribuna", nos permitió recuperar este temprano señalamiento que denunciaba la inconsistencia entre una bienintencionada declaración de principios y una práctica de inclusión paternalista y tutelada. De hecho, el modo en el que los redactores caracterizaban a Eva Duarte, figura política femenina del momento posibilitó entrever, más allá del consabido antiperonismo, la mirada patriarcal con la que juzgaban la participación política de las mujeres.

A pesar de que este trabajo se concentró en un solo periódico, fue posible acceder a dimensiones que atravesaban el anarquismo de esa época y que han sido menos estudiadas que el compromiso sindical o su relación con el peronismo. Al mismo tiempo, confirmar la ausencia de la cuestión sexual como tema central en este órgano de expresión de un sector importante del anarquismo complementa y apuntala, de manera indirecta, los trabajos que documentan el protagonismo de esas temáticas en revistas culturales y proyectos editoriales con presencia anarquista, pero de composición ideológica más ecléctica.

Otro resultado de este recorrido fue detectar la continuidad del tópico emancipación de la mujer entre aquellas encendidas polémicas de fines del siglo XIX y principios del XX, y las décadas que anteceden a la mentada revolución se los años sesenta. Del mismo modo, hemos registrado la recurrencia de las tensiones propias del "concierto de voces" que más que un recitado de consignas es un terreno de intensos debates. Que el soporte de esos 
intercambios sean las revistas y periódicos no hace más que confirmar la necesidad de continuar su estudio en profundidad.

Para volver a AL y finalizar este artículo, debemos señalar que la presencia de Juana Rouco en las actividades de la Federación a fines de los años cincuenta, así como otros indicios en las conferencias que allí se organizaban permiten vislumbrar una reactualización del interés por la cuestión sexual en diálogo con un contexto de transformación de los parámetros en los que se venían organizando las relaciones afectivas y sexuales. La importancia de esos elementos hace preciso dedicarles otro trabajo en el que será fundamental analizar AL hasta su desaparición y, sobre todo, establecer una lectura a contrapunto con otra publicación, cercan a la FACA como "Reconstruir" (1946-1959), y con "La Protesta", periódico que expresa otro espacio del anarquismo activo en esos mismos años.

\section{Referencias bibliográficas}

Diego Abad de Santillán, El movimiento anarquista en la Argentina desde sus comienzos hasta 1910, Buenos Aires, Argonauta, 1930.

Luciana Anapios, El movimiento anarquista en Buenos Aires durante el período de entreguerras, tesis doctoral, Facultad de Filosofía y Letras, Universidad de Buenos Aires, 2012.

Dora Barrancos, Anarquismo, educación y costumbres en la Argentina de principios de siglo, Buenos Aires, Contrapunto, 1990.

Carolina Barry, Evita capitana: el Partido Peronista Femenino, 1949-1955. EDUNTREF, Editorial de la Universidad Nacional de Tres de Febrero, 2009.

Mabel Bellucci, “Anarquismo, sexualidad y emancipación femenina. Argentina alrededor del 900”, Nueva Sociedad, n¹09, 1990, 148-157.

María Eugenia Bordagaray, "Controversias libertarias: La interpelación anarquista en tiempos del peronismo", Tesis doctoral, Facultad de Humanidades y Ciencias de la Educación, Universidad Nacional de La Plata, 2014.

"Luchas antifascistas y trayectorias generizadas en el movimiento libertario argentino (1936-1955)", Cuadernos de H Ideas, n 7, Universidad Nacional de La Plata, 2013.

Diego Ceruso, "El trabajo sindical de base del anarquismo argentino: la FACA y la Alianza Obrera Spartacus", A Contracorriente: una revista de estudios latinoamericanos, $\mathrm{n}^{\circ} 3$, 2011, 233- 254

Richard Cleminson, Anarquismo y sexualidad en España (1900-1939), Cádiz, Universidad de Cádiz, 2008.

José Luis de Diego, (dir.) Editores y políticas editoriales en Argentina, 1880-2000, Buenos Aires, Fondo de Cultura Económica, 2006.

Lucas Domínguez Rubio, "Un itinerario por los proyectos editoriales del anarquismo en Argentina: cambios, maniobras y permanencias", Izquierdas, n 33, 2017, 21 41.

María del Carmen Feijoó, Las feministas, Buenos Aires, Centro Editor de América Latina, 1982. 
Laura Fernández Cordero, Amor y anarquismo. Experiencias pioneras que pensaron y ejercieron la libertad sexual, Buenos Aires, Siglo XXI, 2017.

"Revistas y libros de la cultura sexual libertaria (1930-1950)", XII Jornadas de Sociología Recorridos de una (in)disciplina La Sociología a sesenta años de la fundación de la Carrera, agosto 2017.

"Un ejercicio de lectura sobre el concierto de la prensa anarquista a partir de M. Bajtin (Argentina 1895-1925)", AdVersuS. Revista de Semiótica, n² 24, Buenos Aires, 2013, 6991. 2014.

Michel Foucault, Historia de la sexualidad (Vol. I), Buenos Aires, Siglo XXI editores,

Alejandra Gómez, "Recepción del fenómeno peronista desde el anarquismo argentino: la FACA y su posicionamiento político ideológico en torno a la cuestión agraria y el problema campesino durante los dos primeros gobiernos peronistas (Argentina, 19461955)", inédito.

Osvaldo Graciano, “La escritura de la realidad. Un análisis de la tarea editorial y del trabajo intelectual del Anarquismo argentino, entre los años 30 y el Peronismo", Izquierdas, Santiago de Chile, 2012, 72-110

Isabel Jiménez-Lucena y Jorge Molero-Mesa, “Una dialógica desestabilizadora del orden social y sexual: el médico argentino Juan Lazarte en la revista anarquista Estudios (1932-1936)", Asclepio, Vol. 66, n² 2, 2014, 0-56

Nadia Ledesma Prietto, La revolución sexual de nuestro tiempo. El discurso médico anarquista sobre el control de la natalidad, la maternidad y el placer sexual (Argentina, 1931-1951), Buenos Aires, Biblos, 2016.

Eugenesia y revolución sexual: El discurso médico anarquista sobre el control de la natalidad, la maternidad y el placer sexual. Argentina, 1931-1951. Tesis de Doctorado. Facultad de Humanidades y Ciencias de la Educación, Universidad Nacional de La Plata, Buenos Aires, Argentina, 2014.

“Una genealogía anarquista de la Sexología. Argentina, 1930-1950. Apuntes para su estudio", Jornadas de intercambio del Programa de investigación del Anarquismo (CeDInCI/UNSAM), Buenos Aires, 2018.

Fernando López Trujillo, Vidas en rojo y negro. Una historia del anarquismo en la "Década Infame", La Plata, Letra Libre, 2005.

Fernanda Losso, La intervención discursiva de periódicos escritos por mujeres en la propaganda anarco-comunista, Tesis de Licenciatura, Universidad Nacional de La Plata, 2015.

Eduard Masjuan i Bracons, "Procreación consciente y discurso ambientalista: anarquismo y neomalthusianismo en España e Italia, 1900-1936", Ayer. Revista de Historia Contemporánea, $\mathrm{n}^{\mathrm{O}}$ 46, Madrid, 2002, 63-92.

Maxine Molyneux, "No God, No Boss, No Husband: Anarchist Feminism in Nineteenth-Century Argentina", Latin American Perspectives, Vol. 13, n 1, Latin America's Nineteenth-Century History, 1986, 119-145. Hay versión en español: “Ni Dios, ni Patrón, ni marido. Feminismo anarquista en la Argentina del siglo XIX", La Voz de la Mujer, Periódico comunista-anárquico, Buenos Aires, Universidad Nacional de Quilmes, 1997.

$27-46$

Marysa Navarro, “El liderazgo carismático de Evita”, La Aljaba, La Pampa, 2001,

Evita, Buenos Aires, Editorial Planeta, 1994. 
Agustín Nieto, “Entre anarquistas y peronistas. Organización sindical y experiencias obreras en la industria del pescado, Mar del Plata, 1942-1966", Tesis doctoral, Universidad Nacional de Mar del Plata, 2012.

"Notas críticas en torno al sentido común historiográfico sobre 'el anarquismo argentino'", A Contracorriente. Revista de Historia Social y Literatura en América Latina, n 3 , 2010, 219-248.

1978

Iaacov Oved, El anarquismo y el movimiento obrero en Argentina, México, Siglo XXI,

Pablo Pérez, Juan Manuel Heredia y Hernán Villasenin, “El trabajo cultural del anarquismo. La Biblioteca Archivo de Estudios Libertarios de Buenos Aires (1995-2005) y el Instituto de Documentación Social CNT-FAI (1938)", Germinal: revista de estudios libertarios, $\mathrm{n}^{\mathrm{O}} 2$, 2006, 107-125.

Juan Suriano, Auge y caída del anarquismo. Argentina, 1880-1930, Buenos Aires, Capital Intelectual, 2005.

Anarquistas. Cultura y politica libertaria en Buenos Aires, 1890-1910, Buenos Aires, Manantial, 2001.

Gonzalo Zaragoza, Anarquismo argentino (1876-1902), Madrid, De la Torre, 1996,

Prensa citada:

Acción Libertaria, $\mathrm{n}^{\mathrm{o}}$ 16, 12/1935, 1

Acción Libertaria, $\mathrm{n}^{\mathrm{o}}$ 19, 4/1936, 3

Acción Libertaria, $\mathrm{n}^{\circ}$ 20, 8/1936, 1 y 4

Acción Libertaria, $n^{\circ}$ 26, 4/1937, 1

Acción Libertaria, $\mathrm{n}^{\circ} 31,4 / 1938,1$

Acción Libertaria, $n^{\circ} 33,5 / 1938,6$

Acción Libertaria, $n^{\circ}$ 34, 3/1939, 4

Acción Libertaria, $n^{\circ} 37,6 / 1940,3$

Acción Libertaria, $\mathrm{n}^{\mathrm{o}}$ 50, 11/1941, 1 AL, no 63, 3/1943, 2 L, no 136, 6/1952, 5

Acción Libertaria, $\mathrm{n}^{\circ}$ 96, 12/1946, 2 AL, $\mathrm{n}^{\circ}$ 137, 8/1952, 1

Acción Libertaria, $\mathrm{n}^{\mathrm{o}}$ 141, 10/1953, 4 AL, $\mathrm{n}^{\circ}$ 116, 8/1949, 6-7 